\title{
Contribution to the study of power losses due to friction phenomenon between spur gear teeth
}

\author{
Bernard MUSHIRABWOBA*1, Belfals LAHCEN ${ }^{1}$, Brahim NAJJI², \\ Abdelilah LASRI ${ }^{1}$ \\ ${ }^{1}$ Laboratory of Quality, Security and Maintenance, University Mohammed V Agdal, Rabat, \\ Morocco \\ ${ }^{2}$ Laboratory of Mechanics, Thermics and Materials, Ecole Nationale supérieure des Mines de \\ Rabat, Rabat, Morocco
}

*Corresponding author: E-mail: mubefils@yahoo.fr

\section{Keywords: Spur Gear, Materials, Friction and Wear Power Loss, Gear Efficiency}

\begin{abstract}
This paper aims to present a numerical model to calculate the power losses due to the friction phenomenon in spur geared transmissions which are highly used in many domestic and industrial applications. Since the increase of the power to be transmitted at high rotational speeds result in significant power losses and wear phenomenon, the latter must therefore be taken into account during the different phases especially when designing and choosing the materials of the gears since power losses have direct impact on the lifetime of the power transmitters. The present work gives a better understanding of how to numerically evaluate the friction power losses in spur gears and it is a preliminary study to the future work where the impact of friction and wear phenomena on the material lifetime and energy consumption will be discussed.
\end{abstract}

\section{Introduction}

Nowadays, power transmitters which are mechanical systems or mechanisms that are used to accommodate the power according to the needs are highly used in many of our daily activities. While the popularity of the latter is closely linked to better performance they offer, nevertheless, the increase in power to be transmitted at high rotational speeds results in significant power losses. A well designed mechanical system would enable the user to avoid breakage of the mechanism due to thermal expansion and would allow a better design of the cooling systems. In a geared power transmission system, the total power loss can be divided into load-dependent contribution, the losses due to friction phenomenon for example, and into load-independent contribution which includes the power losses related to the lubrication method, to the ventilation on teeth and to the trapping of the air-lubricant between the teeth. In function of the operating conditions, each power loss category controls the overall efficiency of the system. As cited in [1] and in [2], the friction phenomenon related power losses are preponderant at low speeds whereas they are low at high-speed in comparison to the power losses due to the ventilation phenomenon and to the trapping phenomenon which was discussed by the authors in [3]. In order to understand the friction phenomenon resulting from metal-metal in non-lubricated contacts also known as dry friction, many experiments were conducted. In the case of lubricated contacts there are few models to qualitatively and quantitatively identify the friction phenomenon and its direct influence on power loss in geared power transmissions. In this work a numerical method was developed to calculate the friction power losses assuming the contact between teeth as a lubricated one.

\section{Modelling of meshing and frictional power loss calculation}

By studying the impact of different geometric and operational parameters on the power losses due to friction and by exploiting the documentation on spur gears cited in [4], a numerical modeling was established; using the latter we can instantaneously know the evolution of different meshing parameters along the line of action. The data summarized in the table 1were used in our study: 
TABLE 1. GEOMETRIC DATA

\begin{tabular}{ll}
\hline Parameter & Value \\
\hline Number of teeth (Pinion) & 20 \\
Number of teeth (Wheel) & 40 \\
Module $(\mathrm{mm})$ & 3 \\
Tooth width $(\mathrm{mm})$ & 20 \\
Viscosity (cSt) & 60 \\
Pressure angle (degrees) & 20 \\
Surface roughness parameter $S(\mu \mathrm{m})$ & 0.07 \\
Effective radius of curvature $R(\mathrm{~mm})$ & 5 \\
Maximum pressure of Hertz $P_{h .}(\mathrm{Gpa})$ & 2 \\
Torque $(\mathrm{Nm})$ & 250 \\
Rotational speed (rpm) & 1500 \\
\hline
\end{tabular}

\section{Sliding velocity}

In [4],the sliding velocity is defined as follows:

$$
V_{s}(x)=0.1047(1+1 / i) N\left(x-x_{p}\right)
$$

Where $i$ is the gear ratio, $N$ the rotational speed, $x$ the meshing position along the path of contact and $x_{p}$ the abscissa of the pitch point. Using the data in table 1, we plotted in figure lbelow the sliding velocity in the function of the meshing position.

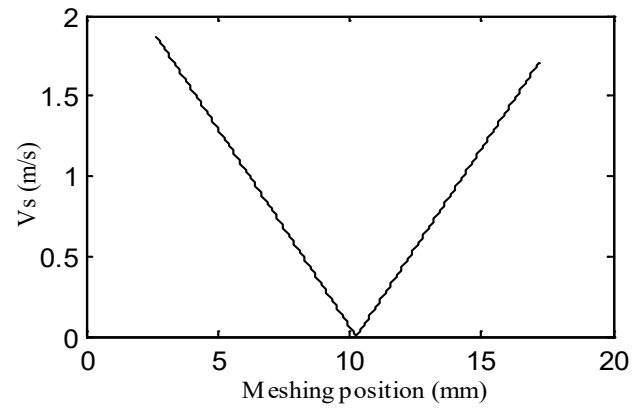

Fig. 1.Variation of the sliding velocity along the line of action

The maximum value of the sliding velocity is found at the starting and ending points of meshing while its minimum value is obtained at the pitch point.

\section{Ceofficient of friction}

The law of friction in this study is given in [5] as follows:

$$
\mu=e^{f\left(S R, P_{h}, v_{0}\right)} P_{h}^{b_{2}}|S R|^{b_{3}} V_{e}^{b_{6}} V_{0}^{h_{7}} R^{b_{8}}
$$

Where: $\quad f\left(S R, P_{h}, v_{0}\right)=b_{1}+b_{4}|S R| P_{h} \log _{10}\left(v_{0}\right)+b_{5} e^{-|S R| P_{h} \log _{10}\left(v_{0}\right)}+b_{9} e^{S}$

$V_{e}$ is the entraining velocity in $\mathrm{m} / \mathrm{s}$, SR the slide to roll ratio and the constants $b_{i}$ are given as: $b_{i}=$ $8.916465 ; 1.03303 ; 1.036077 ;-0.354068 ; 2.812084 ;-0.100601 ; 0.752755 ;-0.390958 ; 0.620305$ for $i=1$ to 9 . The variation of the coefficient of friction during the meshing phase is shown on figure 2 below: 


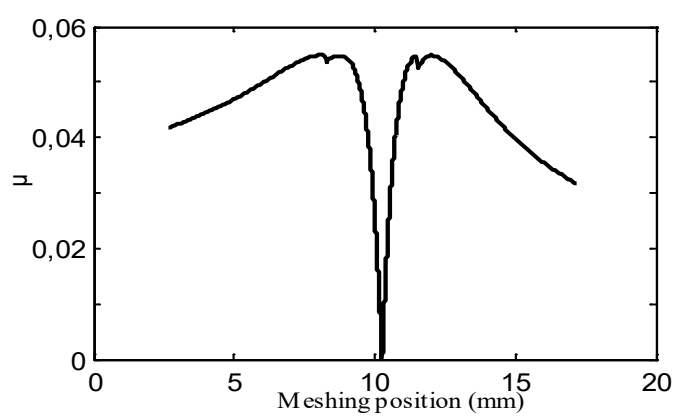

Fig. 2. Variation of the coefficient of friction along the path of contact

The friction coefficient curve shows an increase of the latter from the starting point of meshing and its quick drop near the pitch point is due to the increase of the load in that area.

\section{Sliding power losses}

In spur geared transmissions, the sliding power losses are calculated using the basic Coulomb law:

$$
P_{s}(x)=F_{N}(x) V_{s}(x) \mu(x)
$$

Where: $V_{s}(x)$ is the sliding velocity, $\mu(x)$ the coefficient of friction and $F_{N}(x)$ the transmitted normal load given by:

$$
F_{N}(x)=2 C / d p_{1} \times b \times \cos \theta
$$

With; $C$ the torque, $d p_{1}$ the pinionpitch diameter, $b$ the tooth width and $\theta$ the pressure angle. The sliding power loss is plotted on the figure 3 below

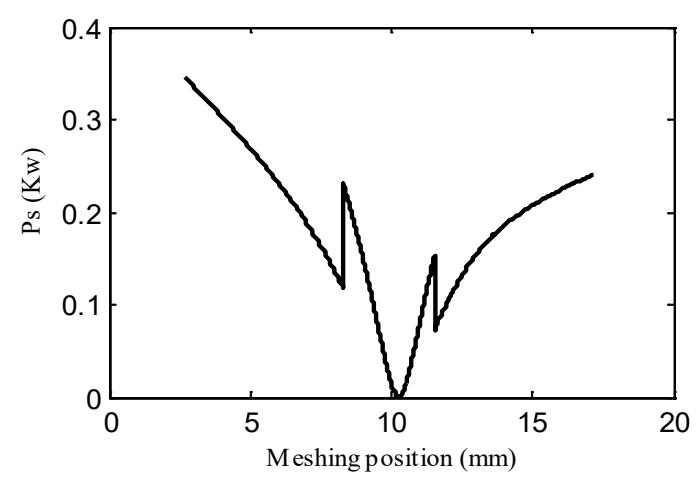

Fig. 3. Variation of the power loss along the line of action

The instantaneous power loss curve shows a minimum value of the sliding power losses which results in the increase of the load and the decrease of the coefficient of friction and the sliding velocity in that area.

\section{Conclusion}

Analytical study on instantaneous sliding power loss in spur geared transmissions was carried out. A numerical model that takes into account different gear parameters in the contact was developed. It allows the user to instantaneously know the sliding power losses at every meshing position along the line of action, in order to evaluate the average power loss; a numerical integration will be used in our 
future work by aiming to study the impact of the friction and wear phenomena to gear material lifetime and energy consumption.

\section{References}

[1] Diab, Y. ; Ville, F. ; Houjoh, H. ; Sainsot, P. ; Velex, P. ; 2004 ; 'Experimental and numerical investigations on the air-pumping phenomenon in high speed spur and helical gears', Proc. IMechE vol. 219 Part c:, Journal of Mechanical Engineering Sciences,2005.

[2] Velex P. and Cahouet, V. « Experimental and numerical investigations on the influence of tooth friction in spur and helical gear dynamics » ASME, J. Mech. Des., 2000, Vol. 122, pp 515-522. http://dx.doi.org/10.1115/1.1320821

[3] Abdelilah Lasri, Lahcen Belfals, Brahim Najji and Bernard Mushirabwoba, "Pressure estimation of the Trapped and Squeezed oil between Teeth Spaces of Spur Gears", Applied Mathematical Sciences, Vol. 8, 2014, no. 107, 5317 - 5328, HIKARI Ltd http://dx.doi.org/10.12988/ams.2014.47542.

[4] Gitin M. Maitra: “Handbook of Gear Design”. Second edition, 1994.

[5] H.Xu, A. Kahraman, N. Anderson, and D. Maddock, "Prediction of mechanical efficiency of parallel-axis gear pairs," ASME, Journal of Mechanical design, Vol, 129, no. 1, p, 58-68, 2007. 